\title{
A Cátedra Unesco-USP de Educação para a Cidadania
}

JOSÉ MÁRIO PIRES AZANHA

$\mathrm{H}$

Á CERCA DE uma década foram publicados dois trabalhos com propósitos diferentes mas que tinham em comum a preocupação com as relações entre democracia e educação.

O interesse em considerá-los aqui, conjuntamente, está no fato de que, apesar de suas diferenças, até mesmo com relação às realidades sociais que tomaram como referência, eles convergiram para uma conclusão idêntica no que diz respeito às relações entre democracia e educação. Em ambos os casos, concluiu-se pelo malogro dos regimes democráticos no cumprimento da promessa educacional.

O primeiro trabalho - um manifesto educacional intitulado A proposta Paidéia - teve como objetivo a indicação de soluções possíveis para que os Estados Unidos pudessem alcançar, ainda neste século, o ideal formulado por John Dewey, em 1916, segundo o qual em uma sociedade democrática todas as crianças deveriam ter não apenas a mesma quantidade mas também a mesma qualidade de educação. Segundo o Manifesto, neste final de século a sociedade norte-americana já conseguiu estender a todos uma escolaridade fundamental de 12 anos, ao cumprir "pela metade a promessa democrática de oportunidades iguais", falindo, porém, no desenvolvimento de um sistema público de ensino que não divida as crianças "em carneiros e bodes, entre aqueles destinados somente ao trabalho árduo e aqueles destinados à liderança política e econômica".

Quanto ao segundo trabalho, O futuro da democracia, seu autor, Norberto Bobbio examinando as transformações da democracia nas sociedades atuais, incluiu "a educação para a cidadania" como uma das promessas não cumpridas pelos regimes democráticos. A propósito desse fato, cita Stuart Mill, o qual, ao lembrar em uma de suas obras que há cidadãos ativos e cidadãos passivos, afirmou que a democracia necessita dos primeiros, mas os governantes muitas vezes preferem os segundos. Talvez estejam aí, insinua Bobbio, as raízes de uma crescente apatia política nos países democráticos apesar dos esforços, nas últimas décadas, dos cientistas políticos com seus discursos em defesa da educação para a cidadania.

Parece-nos que tal conclusão sobre o malogro dos regimes democráticos no alcance de padrões educacionais, exigidos pela própria idéia de cidadania, indica o grande desafio da educação no mundo de hoje, que é simplesmente o da formação do cidadão. Os países desenvolvidos, como afirma o Manifesto Paidéia, cumpriram a tarefa pela metade, ampliando e estendendo a escolaridade fundamental para todos. Resta agora o trabalho de impedir que esse ganho seja anulado por uma escola que marque as crianças para serem, no futuro, separados em cidadãos 
ativos e cidadãos passivos ou, como mencionado cruamente, em bodes e carneiros.

No Brasil, o quadro fica agravado porque, aqui, ainda há crianças sem escolas e a escola pública existente exibe elevados índices de repetência e de evasão. Por isso, dentre os vários encaminhamentos possíveis para as atividades da Cátedra Unesco, "nenhum sobreleva em importância" aquele que se refere ao problema da democratização do ensino fundamental público, porque com relação a ele nem mesmo foram cumpridas as metas de sua universalização. Ao propor a questão nesses termos não se desconhece a abrangência da iniciativa conjunta da Unesco e da USP, mas pretende-se apenas indicar a prioridade democrática do ensino fundamental, pois é nele que se enraízam destinos pessoais e situações sociais que convivem diuturnamente com a intolerância e a violência.

Não se trata pois de descartar de plano a relevância de outras questões educacionais e sociais como objetos de reflexão e de pesquisa no âmbito das atividades da Cátedra. Aliás, se houvesse esse estreitamento, haveria uma indesejável redução dos propósitos políticos da iniciativa da Unesco e da USP a uma questão pedagógica. Não se pretende essa redução, mas a fixação do entendimento de que - no quadro das nossas carências sociais - os esforços para repensar a formação básica do cidadão, em todas as suas dimensões, têm importância e urgência maiores do que nos países mais desenvolvidos. A participação nesses esforços deve ser a vocação da Cátedra que ora se instala.

O fato de que países do mundo desenvolvido, não obstante a completa extensão da escolaridade básica, tenham malogrado quanto à formação para a cidadania apesar dos discursos e dos esforços de organizações governamentais e não-governamentais, sugere que o nó da questão pode estar no próprio universo das práticas escolares. Muitas vezes, a exaltação dos valores democráticos atinge a escola apenas retoricamente por meio de rituais - inerentes ao exercício da democracia no campo político - mas que, transplantados para o mundo escolar, se transformam num alegre e inconseqüente faz-de-conta pedagógico que convive com práticas escolares marcadamente antidemocráticas. A formação para a cidadania exige a alteração de tais práticas. Por isso, é de alto interesse que a Cátedra Unesco estimule a investigação empírica e a reflexão que permitam identificar as práticas e os padrões de convivência, presentes e rotineiros na vida escolar, mas que se afastam e até mesmo contrariam os autênticos valores da vida democrática.

Referências bibliográficas

ADLER, Mortimer Jerome. A proposta Paidéia. Trad. de Marília L. Couri. Brasília, Editora Universidade de Brasília, 1984.

BOBBIO, Norberto. O futuro da democracia, $5^{a}$. ed. Trad. de M.A. Nogueira. São Paulo, Paz e Terra, 1992.

José Mário Pires Azanha é coordenador da Cátedra Unesco de Educação para a Paz, Direitos Humanos, Democracia e Tolerância na USP e professor da Faculdade de Educação da USP. 


\title{
Criação e implantação da Cátedra Unesco-USP
}

\author{
FLÁVIO FAVA DE MORAES
}

$\mathrm{P}$ OR INICIATIVA DA Unesco e da Universidade Federal do Rio de Janeiro realizou-se naquela cidade, de 12 a 16 de setembro de 1994, o Encontro sobre Tolerância na América Latina e no Caribe, sob a coordenação da professora Vera Vidal, docente daquele Instituto. Tivemos a oportunidade de participar do evento na qualidade de conferencista. Nessa ocasião, propusemos a conveniência de uma mais estreita colaboração entre a Unesco e a USP. Logo, no retorno desse encontro, formalizamos tal proposta encaminhando à Unesco (Serguei Lazarev, Divisão de Filosofia e Ética) uma sugestão preliminar para a realização, na USP, de um seminário que teria "como meta discutir os principais papéis desempenhados pelas Ciências na constituição da solidariedade como um processo, tendo em vista a melhoria das condições da vida humana com ênfase especial na responsabilidade dos cientistas no que concerne a esses papéis...".

Ainda, no âmbito do Encontro do Rio, cogitou-se a idéia de criação de uma Cátedra da Unesco, sediada na USP, a exemplo de iniciativas semelhantes em várias partes do mundo, conforme sugestão já feita por Celso Garbarz, do Comitê Internacional Executivo da Anistia Internacional, em abril de 1994. Em conseqüência dessa idéia, solicitamos informações à Unesco sobre o assunto (Janusz Symonides, Divisão de Direitos Humanos, Democracia e Paz), ao mesmo tempo em que pedimos o apoio a esse pleito. Segundo a orientação recebida, dirigimo-nos ao senhor Federico Mayor, diretor geral da Unesco, no final de 1994, fazendo a proposta formal de criação da referida Cátedra. No início de 1995 recebemos resposta favorável e, posteriormente, minuta do contrato que concretizaria a iniciativa conjunta da Unesco e da USP.

Em março, a Reitoria encaminhou à Unesco correspondência acerca do contrato proposto, analisado e assinado, designando ao mesmo tempo os professores doutores Nachman Falbel (FFLCH) e Roseli Fischmann (FE) "para a preparação dos subsídios e para o acompanhamento pela USP das providências referentes à concessão e planejamento da Cátedra".

Em seguida, o Instituto de Estudos Avançados (IEA) foi consultado sobre a possibilidade de sediar a Cátedra, em cuja criação a USP tanto se empenhara. Com a anuência de seu Conselho Deliberativo à consulta, o próprio Instituto designou comissão especial para "estabelecer o perfil e as linhas de atuação da Cátedra" a partir de consultas a professores e pesquisadores de outros institutos, incluindo aqueles que, por designação da Reitoria, vinham prestando assessoria para que se pudesse firmar o Convênio (Agreement) que institucionalizaria a criação e a implantação da Cátedra. 
Em setembro, o professor Umberto Cordani esteve em Paris, discutindo os termos do convênio entre Unesco e USP e, no seu retorno, promoveu reunião especial à qual compareceram Alfredo Bosi, Betty Mindlin, Dina Kinoshita, Kabengele Munanga, Marco Antonio Tavares Coelho, Maria Victoria Benevides, Nachmann Falbel, Rosa Esther Rossini, Roseli Fischmann e Sérgio Adorno.

Finalmente, em novembro, a Reitoria recebeu cópia do Convênio (Agreement) já assinado pelo diretor geral da Unesco e, assim, com nossa assinatura, oficializou-se a criação da Cátedra Unesco-USP de Educação para a Paz, Direitos Humanos, Democracia e Tolerância.

O IEA, dando prosseguimento aos preparativos para a implantação da Cátedra, propôs o texto do que viria a ser a Portaria-GR n ${ }^{\circ} 2983$, de 17 de janeiro de 1996. Nos termos dessa Portaria, encaminhou à Reitoria lista tríplice para a escolha do responsável (coordenador) pela Cátedra bem como a indicação dos membros do Conselho de Coordenação que, inicialmente, ficou assim composto: Paulo Sérgio Pinheiro, Maria Victoria Benevides, Kabengele Munanga, Nilson José Machado, Alberto Castiel, Margarida Genevois, Fábio Konder Comparato, Celso de Rui Beisiegel, Dina Kinoshita e Oded Grajew. Como responsável foi designado José Mário Pires Azanha.

Em resumo, o processo de criação da Cátedra Unesco-USP de Educação para a Paz, Direitos Humanos, Democracia e Tolerância, primeira em país de língua portuguesa, desenvolveu-se ao longo de dois anos, desde as primeiras discussões até a sua instalação. O êxito da iniciativa foi fruto do empenho das pessoas referidas nesta breve notícia, com especial destaque aos esforços de Roseli Fischmann e de Nachmann Falbel, no Brasil, e de Serguei Lazarev e Janusz Symonides, na França, sede da Unesco.

Flávio Fava de Moraes é reitor da Universidade de São Paulo. 


\title{
Cooperação entre a Cátedra Unesco-USP e a Faculdade de Educação da USP
}

\author{
JOSÉ SÉRGIO CARVALHO
}

$\mathrm{N}$ O DOCUMENTO intitulado Linhas de Atuação da Cátedra Unesco-USP, aprovado pelo Conselho Coordenador da Cátedra, esta instituição declarou ser um de seus objetivos "articular-se com instituições que atuam na área temática da Cátedra, com vistas a definir formas de colaboração e de participação... [em] iniciativas da própria Cátedra ou outras que se situem no âmbito de sua temática". Dada a importância dessa iniciativa para a área educacional, o documento foi apresentado e discutido em reuniões da área de Filosofia da Educação e do Conselho do Departamento de Filosofia da Educação e Ciências da Educação da Faculdade de Educação da USP, ocasiões em que, pela primeira vez, se aventou a possibilidade de se desenvolver algum trabalho conjunto entre a Cátedra e a Faculdade de Educação da Universidade de São Paulo.

Nessas reuniões a idéia de estabelecer-se uma cooperação entre essas duas instituições foi considerada não só como bastante viável, mas muito interessante, uma vez que há várias preocupações em comum entre ambas. A própria temática ao redor da qual criou-se a Cátedra já ensejava uma aproximação em relação ao departamento e à faculdade. Ela não se volta simplesmente para pesquisas e reflexões sobre problemas ligados a Democracia, Paz, Direitos Humanos e Tolerância, mas busca tratar de problemas da Educação voltada para esses objetivos. Além disso, o fato de a Coordenação da Cátedra ser exercida por um membro desta faculdade, bem como de seu Conselho Coordenador contar com três professores também desta instituição, tornava a possível cooperação, no mínimo, potencialmente mais simples e frutífera.

Inúmeras formas de cooperação surgiram como hipóteses de trabalho, mas há um aspecto do documento que ensejou a primeira sugestão de trabalho conjunto, que acabou por ser implementado já no primeiro semestre letivo de 1997. O último dos itens do documento sobre Linhas de Atuação relativo às Políticas Públicas de Educação e Organização Curricular propõe como metas: a "emissão de pareceres e sugestões sobre aspectos de políticas públicas de educação que sejam relevantes do ponto de vista da Cátedra"; e "investigações sobre formas de aproximação entre currículos e programas escolares, nos diversos níveis de ensino, e os temas relativos aos direitos humanos, à democracia, à paz e à tolerância, visando ações efetivas, no âmbito da escolarização formal". 
Tais metas fundamentam-se nos próprios objetivos da Unesco de ampliar a preocupação com a temática da Cátedra para os mais diversos segmentos sociais, notadamente aqueles ligados à educação formal de primeiro e segundo graus, de forma que as atividades da Cátedra não se circunscrevam exclusivamente a atividades acadêmicas.

Assim, a partir de uma sugestão da área de filosofia do Departamento de Filosofia da Educação e Ciências da Educação, passamos a discutir a possibilidade de uma redefinição dos programas e objetivos da disciplina Introdução aos Estudos em Educação (EDF 283), disciplina inicial de todos os alunos da Universidade de São Paulo que se inscrevem no programa de licenciatura. Desde sua implantação, a disciplina teve como objetivo oferecer aos alunos uma visão mais ampla do processo educacional em seus aspectos sociais e históricos, daí sua precedência com relação às disciplinas mais técnicas ou específicas, como as de Didática e Práticas de Ensino. Um eventual acordo com a Cátedra não alteraria, portanto, os objetivos gerais de uma iniciação global às questões de educação, mas a eles adicionaria uma possibilidade integradora: a preocupação de uma vinculação entre a educação escolar e a formação voltada para os valores da paz, dos direitos humanos, da democracia e da tolerância.

A idéia básica que animou esse tipo de reformulação foi a de iniciar a licenciatura por meio de uma disciplina que pudesse oferecer ao aluno uma visão de que os problemas relativos à educação não se resumem a problemas de técnicas ou de procedimentos didáticos supostamente mais eficazes. Ao contrário, a ação educativa pressupõe certas tomadas de posição e certas avaliações irredutíveis às especificidades metodológicas. Assim, opções de natureza metodológica, didática e mesmo curricular devem ser cultural e logicamente derivadas de objetivos e valores e não o contrário.

Evidentemente a necessária vinculação de qualquer prática educacional a um conjunto de valores, que implícita ou explicitamente com ela se articula, pode ser tratada a partir de diversas perspectivas. A que sugerimos, vinculando os objetivos da ação escolar aos ideais de democracia, cidadania e tolerância, tem como meta não exatamente a exposição dos alunos a uma retórica a respeito das vinculações entre a educação e esses valores, mas buscar impregnar o professor com esse tipo de preocupação de forma que sua prática pedagógica reflita tal diretriz geral e promova a concretização desses valores. Não se trata, portanto, de produzir discursos sobre esses temas que, na melhor das hipóteses, seriam reproduzidos aos seus futuros alunos. A idéia é que cada professor, a partir dos conteúdos e práticas que lhe são específicas em função da especialidade de sua disciplina, das opções metodológicas e do projeto escolar em que se insere, possa estar atento às questões relativas à promoção de uma conduta democrática e tolerante.

Nesse sentido, o novo curso de Introdução aos Estudos de Educação, fruto desse acordo aprovado tanto pelo Departamento de Filosofia da Educação e Ciências da Educação como pelo Conselho da Cátedra, foi estruturado a partir de reflexões em torno dos seguintes problemas: 
- Educação, direitos humanos e cidadania.

- A democratização da educação em nível escolar.

- O princípio da igualdade e as práticas escolares.

- A instituição escolar e a violência.

- A convivência escolar como oportunidade de cultivo da tolerância.

Tais eixos temáticos emergiram de uma reunião com coordenadores de áreas e professores que estão ministrando a disciplina neste semestre. A abertura de cada um dos blocos temáticos tem sido feita por alguém do próprio Conselho da Cátedra (1), ou por ele sugerido, e é comum a todos os alunos matriculados em turmas que seguem a sugestão de ementa feita a partir do convênio. Em seguida, cada professor desenvolve o tema em questão, a partir de uma seleção de textos, científicos, históricos, filosóficos e literários, ao longo das três aulas seguintes. A bibliografia para a discussão do tema ficou a cargo dos professores do departamento e do Conselho da Cátedra. A cada professor responsável por uma turma coube fazer as opções ulteriores, de acordo com sua formação ou escolha.

Neste primeiro semestre de implantação do programa, a adoção dessa linha que vincula a disciplina Introdução aos Estudos em Educação à temática da Cátedra foi optativa para os docentes do departamento e dentre as 11 turmas, seis aderiram ao novo programa. Ao final do primeiro semestre de 1997, os professores que tomaram parte no programa deverão proceder a uma avaliação, a ser entregue ao departamento e à Cátedra, para uma possível reformulação da ementa ou das estratégias do curso. As seis turmas vinculadas ao projeto contam ainda com a assistência de cinco monitores do Programa de Aperfeiçoamento do Ensino (PAE), que têm se reunido quinzenalmente com os professores a fim de discutir e avaliar o andamento do curso, além de preparar textos e estratégias de aula e leitura.

É importante ressaltar o fato de que, tratando-se de uma temática transversal, a abordagem das questões relativas a democracia, cidadania, direitos humanos e tolerância pode ter perspectivas das mais diversas áreas que compõem o departamento. Assim, a temática permite simultaneamente unidade de objetivos e respeito à formação dos professores que nela eventualmente se engajem, abrindo a possibilidade de que, no futuro, novas disciplinas integrantes da licenciatura possam se aproximar dos ideais do projeto.

Cabe ainda destacar que a implementação do programa exigiu não simplesmente uma mudança da ementa do curso, mas a disponibilidade de participação dos professores responsáveis pela disciplina na discussão e elaboração - e posterior avaliação - do projeto e, em grande medida, é a esse empenho coletivo que podemos atribuir o êxito da proposta, já possível de ser inferida a partir de avaliações informais junto aos alunos, bem como da presença maciça nas palestras e aulas.

Esperamos, portanto, que tal proposta possa significar mais do que uma colaboração específica e restrita à abordagem da disciplina em questão. Nosso intuito é que, a partir dela, a Cátedra e a faculdade iniciem um diálogo que possa 
ser fecundo para ambas as instituições (2) e que resulte em sugestões para uma política de formação de professores e pesquisadores envolvidos com os problemas relativos às ligações entre a escolaridade e os valores de cidadania, democracia, paz e tolerância.

\section{Notas}

1 Os cinco palestrantes deste semestre são, respectivamente, professores doutores Maria Victória Benevides Soares, Lisandre Maria Castello Branco, Fábio Konder Comparato, Marília Pontes Spósito e Nílson José Machado.

2 Esta proposta de cooperação também foi apresentada no Encontro sobre Formação de Professores na UfsCar, em maio de 1997. Fizemos na ocasião contatos com responsáveis pela Licenciatura em outras universidades estaduais a fim de, eventualmente, estender o programa ou seus objetivos a outros cursos de licenciatura no estado de São Paulo.

José Sérgio Carvalho é professor da Faculdade de Educação da USP. 


\title{
Linhas de atuação da Cátedra Unesco-USP
}

\author{
CONSELHO COORDENADOR
}

$\mathrm{O}$

CONSELHO COORDENADOR da Cátedra Unesco-USP, ao explicitar as linhas de atuação para suas atividades no período 1996-97, apenas pretende uma primeira delimitação do campo de suas principais iniciativas. Tal delimitação levou em conta não apenas as expectativas presentes ou sugeridas no Acordo Unesco-USP que instituiu a própria Cátedra, como também a orientação esboçada nos documentos preliminares preparados pelos membros do Conselho Coordenador. Cada linha foi proposta apenas como indicação dos interesses prioritários que deverão ser considerados na formulação de projetos próprios ou de participação da Cátedra em projetos de outras instituições.

O Conselho Deliberativo do Instituto de Estudos Avançados da USP aprovou as linhas de atuação para a Cátedra descritas a seguir, capacitando-a para:

- tomar providências para formular e executar diretamente projetos específicos, e convidar especialistas ou entidades que se disponham a assumir as responsabilidades de formulação, coordenação ou execução de projetos;

- articular-se com instituições que atuam na área da temática da Cátedra, com vistas a definir formas de colaboração e de participação;

- estabelecer contatos com todos os meios de comunicação para instituir canais regulares para divulgação de iniciativas da própria Cátedra ou outras que se situem no âmbito de sua temática.

Este documento é complementado por outro, reunindo os textos preliminares de autoria dos membros do Conselho de Coordenação que contém também a explicitação dos princípios básicos orientadores de todas as atividades da Cátedra.

\section{Publicações}

\section{Objetivos}

- Seleção de textos clássicos que sejam fundamentais para o estudo, em nível superior, da temática da paz, dos direitos humanos, da democracia e da tolerância;

- indicação de assuntos vinculados a essa temática, que sejam interessantes para a produção, publicação de textos paradidáticos nos níveis do ensino fundamental, médio e superior e de outros textos destinados a iniciativas específicas. 


\section{Justificativa}

A própria Unesco publicou, em 1951, uma lista de mais de 150 títulos como sugestão de uma "bibliografia selecionada de textos sobre democracia e seu papel nos conflitos ideológicos". Decorrido quase meio século desde essa iniciativa, conviria que a Cátedra ampliasse os limites dessa sugestão e estimulasse providências editoriais para que se venha a dispor, em língua portuguesa, não apenas de textos clássicos mas também de textos paradidáticos que possam compor uma bibliografia a ser utilizada em todos os níveis de ensino, bem como em campanhas e cursos especiais.

\section{Estudos teóricos e pesquisas de campo}

\section{Objetivos}

- Realização de estudos e pesquisas sob a responsabilidade direta dos membros da Cátedra ou de especialistas ou instituições por ela convidados;

- estímulo à criação, no âmbito de programas de pós-graduação, de linhas de pesquisa no campo da educação para a democracia, os direitos humanos, a paz e a tolerância.

\section{Justificativa}

No cenário intelectual brasileiro, ao longo do tempo, têm prevalecido as investigações individuais com relação a democracia, direitos humanos e temas correlatos. Muitas vezes, essas investigações ocorreram fora do ambiente acadêmico. Na universidade, é relativamente recente o surgimento de grupos, com diferenciados graus de institucionalização, dedicados à investigação sistemática e interdisciplinar nessa área. Nesse quadro, o papel da Cátedra poderá ser de muita importância no desempenho de ações que ampliem o espaço institucional necessário ao aumento do número de investigações na área, especificamente voltadas para a realidade educacional brasileira.

\section{Documentação}

\section{Objetivos}

- Organização de um cadastro nacional de órgãos governamentais, nãogovernamentais e de investigadores individuais que, de alguma forma, estejam empenhados no estudo, na promoção ou na defesa dos direitos humanos;

- organização de um centro de documentação que procure reunir materiais relevantes relativos à temática da Cátedra, especialmente aqueles produzidos no Brasil ou pela Unesco. A constituição desse acervo deverá ter ampla divulgação, não apenas para incentivar a colaboração de entidades e de pessoas, mas também informar sobre a disponibilidade para consultas de todos os interessados. 


\section{Justificativa}

O próprio Acordo Unesco-USP prevê a necessidade de "promover um sistema integrado de pesquisa, formação, informação e documentação sobre o tema dos direitos humanos, democracia e paz". É evidente que a promoção dessa integração de esforços depende, em primeiro lugar, de um mapeamento nacional das instituições, dos grupos e das pessoas que venham de maneira sistemática empreendendo ações ou promovendo eventos os quais, pelos seus propósitos, se relacionem com a temática da Cátedra. Mas, além da organização desse cadastramento, convém que se inicie de forma sistemática a constituição de um acervo de boletins, revistas e livros que reúna, inicialmente, todo material relevante disponível no Brasil e na Unesco. Tal acervo, independentemente de outras iniciativas, poderá ser um poderoso estímulo ao desenvolvimento de novos estudos e de ampliação do interesse na área dos direitos humanos.

\section{Cursos, seminários, conferências}

\section{e participação em eventos}

\section{Objetivo}

- Promoção ou participação em cursos, seminários, conferências ou outros eventos vinculados à temática da Cátedra.

\section{Justificativa}

A própria Cátedra deve tomar algumas iniciativas, principalmente no âmbito da USP, visando à realização de conferências temáticas de forma a abranger diferentes perspectivas disciplinares, conduzindo à eventual organização e publicação de volumes da Coleção Documentos - Série Cátedra Unesco-USP. Além de iniciativas próprias, convém que a Cátedra procure integrar-se, institucionalmente ou pela participação individual de seus membros, em cursos, seminários ou eventos similares, sempre que os propósitos dos mesmos se vinculem à defesa dos direitos humanos, principalmente naqueles casos que visam a preparação de docentes ou outros grupos cujo trabalho seja uma oportunidade permanente de promoção e defesa dos direitos humanos, da paz, da tolerância e da democracia.

\section{Políticas públicas de educação \\ e organização curricular}

\section{Objetivos}

- Emissão de pareceres e de sugestões sobre aspectos de políticas públicas de educação que sejam relevantes do ponto de vista da temática da Cátedra;

- investigação sobre formas de aproximação entre os currículos e os programas escolares, nos diversos níveis de ensino, e os temas relativos aos direitos humanos, à democracia, à paz e à tolerância, visando a propostas de ações efetivas, no âmbito da escolarização formal. 


\section{Justificativa}

A escola, em seus diversos níveis, é um local especialmente importante no cultivo de valores, na construção da cidadania. É fundamental, portanto, que o debate sobre a temática da Cátedra encontre formas de influenciar as políticas públicas de educação, os currículos e os programas escolares, desde a escolarização básica até o ensino superior.

Uma interpretação tempestiva das recomendações constantes no próprio texto do Acordo Unesco-USP conduz, naturalmente, à exclusão tanto da meta da elaboração de um currículo em sentido estrito, quanto da mera discussão sobre a conveniência ou não de se introduzir uma nova disciplina abrangendo os direitos humanos ou temas correlatos.

Outras formas de aproximação devem ser buscadas, envolvendo, eventualmente, novos modos de articulação entre as disciplinas já existentes, ou de tratamento dos temas examinados nas mesmas, numa perspectiva transdisciplinar.

Certamente a escola não é o único espaço para a reflexão sobre tais temas, para a construção da cidadania, mas é um espaço privilegiado que precisa ser administrado de modo mais eficaz. Parece indispensável a busca de uma articulação mais consistente entre as reflexões teóricas realizadas no âmbito da Cátedra e as ações e os planos governamentais, principalmente no que diz respeito aos espaços dos currículos e programas regulares.

RESUMO - O conjunto dos quatro textos contém um breve histórico dos esforços para a criação da Cátedra Unesco-USP de Educação para a Paz, Direitos Humanos, Democracia e Tolerância; documento preliminar sobre o significado da Cátedra no panorama educacional brasileiro; notícia sobre um dos principais projetos em desenvolvimento referente à formação de professores; linhas de atuação do órgão. .

ABSTRACT - This set of four documents presents a brief historical note on the efforts to create the Unesco-USP Chair on Education for Peace, Human Rights, Democracy and Tolerance; an introductory document on the significance of this Chair in the Brazilian educational outlook; a brief note on one of the main projects being presently developed concerning teacher's training courses at the university; the plan of actions of the institution. 